\title{
Climate change, regime shift and stock management
}

\section{TSUYOSHI KAWASAKI}

\author{
Professor emeritus at Tohoku University,Kugenuma-Fujigaya 1-10-6,Fujisawa 251-0031,Japan
}

SUMMARY: As more and more data of long-term variability in marine organisms from phytoplankton to predatory fish accumulate, a persistent pattern of the interdecadal and global scale, regime shift, is emerging. Many of the fish populations are growing and declining rhythmically with a high degree of synchrony. A skyrocketing improvement in chum salmon's rate of return to Japan as brought about by a technological innovation is now unacceptable and it seems to embody the regime shift. Abundant evidence in support of the regime shift has been given recently for the variability in climate-ocean system, which suggests that climate change may be the driving force linking the variations in marine populations. There are some forerunning studies that lead to mechanisms causing global concurrence in ocean enrichment. In the traditional population dynamics that has underlain the current stock management regime and enhancement programs, it is assumed that a fish population is in equilibrium with the fishing effort under average environmental conditions. Change in biomass due to environmental variations is regarded as a noise and hence an unfished population remains unchanged. The theory, however, has turned out inconsistent with the real world and it needs be examined.

\section{KEY WORDS : regime shift, climate change, sardines, tunas, skipjack, chum salmon}

\section{INTRODUCTION}

Since the simultaneous rise and fall of the interdecadal and global scale of sardine populations was first pointed out by Kawasaki ${ }^{1)}$ (Fig.1), many other similar events of long-period variability in marine organisms from phytoplankton to predatory fish have been emerging, which is called regime shift.

Venrick et $a l^{2)}$ show significant shifts in phytoplankton production (integrated chlorophyll a) just north of Hawaii in the mid-1970s. In the Central Subarctic Domain summer zooplankton biomass more than doubled between the late 1950s and 1980s 3). Since the mid-1970s, the individual growth of Pacific halibut in the North Pacific has decreased and recruitment has increased drastically ${ }^{4)}$. Most major flatfish species in the Gulf of Alaska and the Bering Sea increased in concert with other groundfish from the mid-1970s to mid-1980s, but either remained at high levels (yellow sole) or continued to increase into the early 1990s (arrowtooth flounder and rock sole) ${ }^{4)}$. Long-term catches of the herrings and anchovies show trends inphase with but different in sign from the sardines ${ }^{5)}$

\section{NEW EVIDENCE IN SUPPORT OF REGIME SHIFT THEORY}

\section{Northwestern Pacific tunas}

In Fig. 2, CPUE, annual catch of tunas by the Japanese

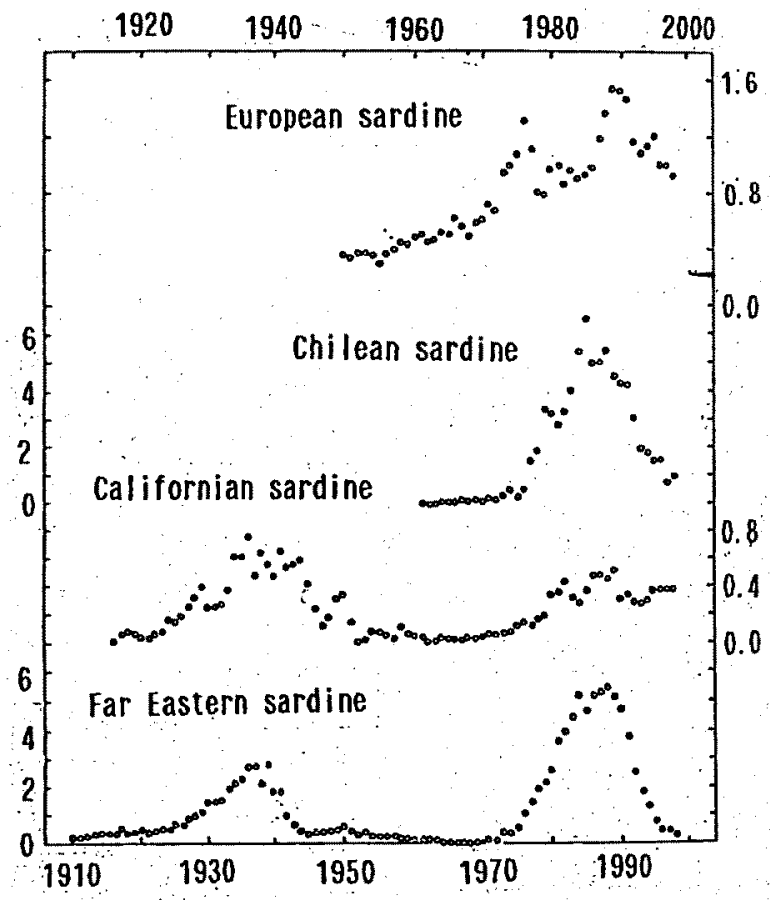

Fig. 1 Timeseries of catch in villion tonnes of four sardine populations in the world.

coastal tuna longliners under a tonnage of 20 , operating in the northwest Pacific Ocean $(0-40 \mathrm{~N}$, west of $160 \mathrm{E}$ ), per fishing effort, the number of days fishing, is regressed against the fishing effort during the period between 1973 and 1999. The number of days fishing has been increasing almost year by year, and the scale on abscissa of Fig. 2 corresponds 


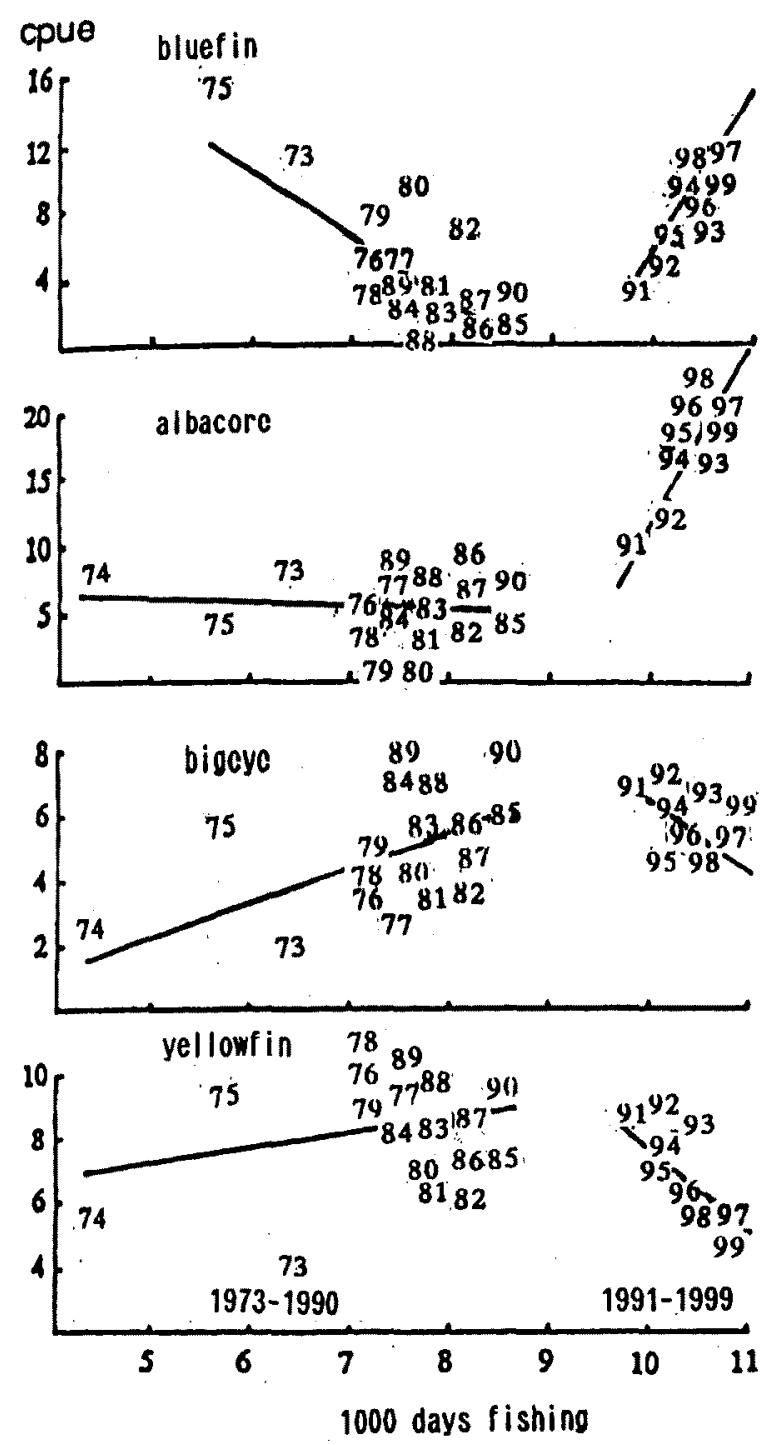

Fig. 2 Annual catch per fishing effort regressed against fishing effort, the number of days fishing. for the four luna populations, bluef in, albacore, bigeye and yellowfin, by the Japanese coastal tuna longline fishery in the northwestern Pacific. CPUE is expressed in $\mathrm{kg} /$ day for the bluefin and in $10 \mathrm{~kg} /$ day for the others.

roughly to the calendar year. Four tuna species, bluefin, albacore, yellowfin and bigeye, are primarily targeted by the fishery. The regressive relations of CPUEs against fishing effort for the four tunas in the northwest Pacific are divided into two categories: one including bluefin and albacore and the other yellowfin and bigeye. The two categories show fluctuation patterns completely opposite to each other, the former concave and the latter convex, which implies that the trends in biomass of bluefin and albacore were reversed from decline to growth and in the opposite way for the yellowfin and bigeye, with an inflection in 1990-91.

Around 1990-91, the sardine and herring populations in the world oceans marked peaks and troughs of their biomass, respectively 5), which indicates that the pattern of regime shift of bluefin and albacore inhabiting temperate waters is of a herring type and that of yellowfin and bigeye with their habitat in tropical oceans is of a sardine type. The new evidence for the regime shift as to the fish at higher trophic levels strongly suggests that climate change has an impact directly on even piscivorous fish without passing through the food chain, showing that the regime shift is a universal principle which is common to most fish groups.

\section{Skipjack tuna off the eastern coasts of Japan}

Skipjack tuna which make northward migration during spring to early summer to the waters east of Japan and leave there for the south in fall comprise five groups, $A$ to $E$, categorized by the time and size at run. Group $\mathrm{C}$ which has been born in the tropical waters in winter and moves to the north the next year is most dominated ${ }^{6)}$. Most of the skipjack caught there have been landed to seven fish markets on the east coasts of Honshu, Japan, Kesennuma, Onagawa, Ishinomaki, Shiogama, Onahama, Nakaminato and Choshi in order of north-to-south, of which here we call the former four markets the northern markets and the latter three the southern.

Fig. 3 shows year-to-year change in landings of the skipjack tuna (exclusive of frozen fish, threeyear running mean) to the northern, southern markets and combined. The Kuroshio Current flows offshore after running along the southern coasts of Japan and most of the landings to the northern markets come from the fishing made north of the Kuroshio Front and those to the southern markets from the other side. The landings to the northern markets which had been on the decline since the mid-1960s reversed to the rise in the mid-1970s to reach a very high level in the late 1990s. On the other hand, the landings to the southern markets show a trend opposite to the northern markets and the trend in the combined landings is similar to those to the northern markets, reflecting that the landings to the northern markets have been more abundant than to the southern markets.

According to Nihira 6), "As more biomass the skipjack population gains, there is an increasing tendency of fish schools to cross over the Kuroshio Front toward the Transition Area". Therefore, the rise 


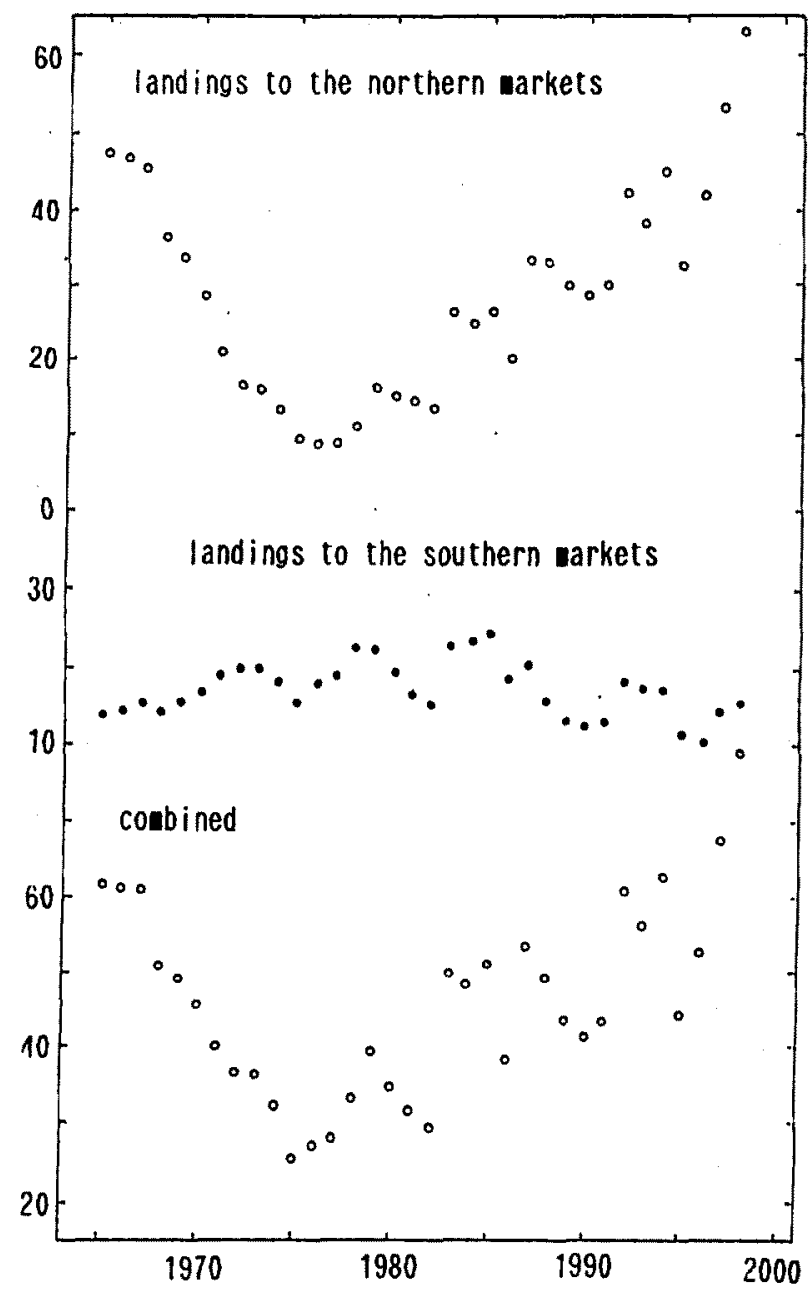

Fig. 3 Year-to-year change in landings in thousand tonnes of skipjack tuna to the northern lish arkets(Kesennuma, onagawa. Ishinomaki and Shiogana), southern

arkets (Onahana, Nakaninato and Choshi) on the eastern Honshu coast of Japan and combined. Three-year running aean.

in skipjack landings to the northern markets implies an upward trend in the skipjack population. More landings to the southern markets under smaller biomass indicate that skipjack were packed into the waters just south of the Kuroshio Front.

\section{Salmon enhancement in Japan}

In autumn, chum salmon released from Japan return to the coasts of Hokkaido and northern Honshu. Since the reproduction of chum salmon in Japan these days depends mostly on artificial seeds, the number of returns to Japan is defined by both the number of liberated fry and their return rate. The number of fry increased rapidly in the 1970 s to some 2 billion, followed by a level-off period (Fig.4). Although the number of returns rose sharply from 3.7 million in 1962 (mostly 1958 year-class) to 88 million in 1996 with increasing releases, it fell afterwards to 44 million in 2000 , about a half of the most abundant returns. The return rate went up from $0.5-1.0 \%$ for the 1962-65 year-classes and attained $4.5 \%$ for the 1992 year-class but it dropped down to $2.3 \%$ for the 1996 year-class, almost a half of the peak values.

In general, individual fish grows faster with declining biomass. Since the average weight of returned fish is negatively related to the number of returns (Fig.4), the fluctuations in returns are deemed to show variations in biomass. It is undoubted that the increase in releases of chum salmon fry had contributed to the augmentation in returns until 1986 but the crucial problem is the evaluation of return rate. Fisheries Agency of Japan stressed an advance in fry rearing and liberation technologies as they contributed to the increase in returns of the chum salmon ?). Beginning with the 1993 year-class, however, the return rate has reduced and in the 1996

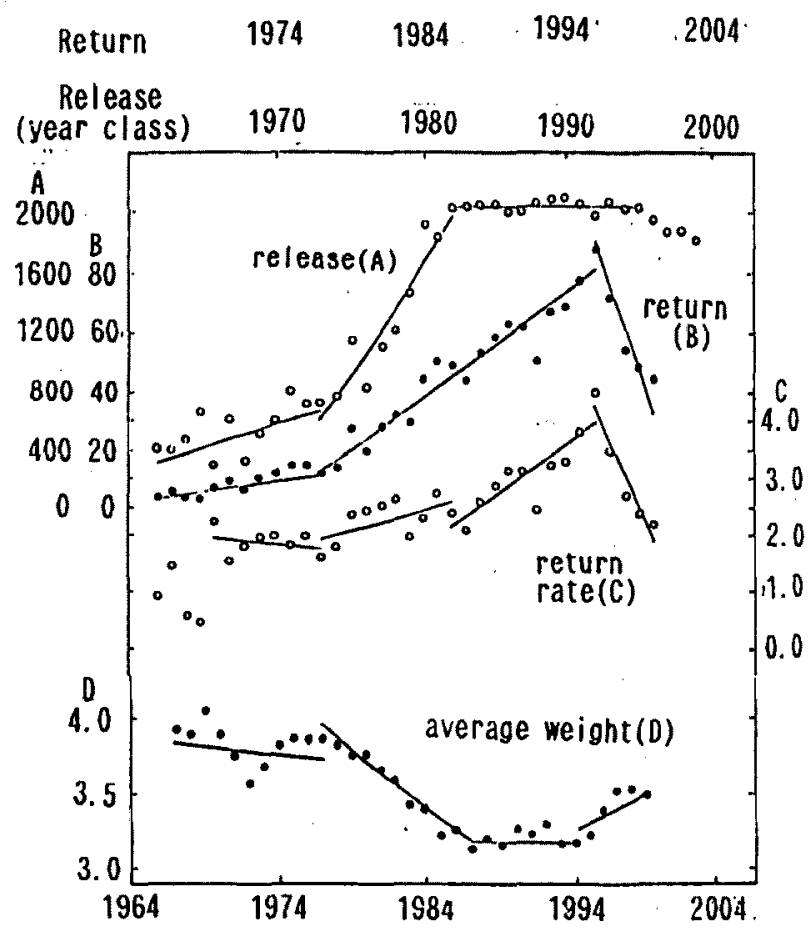

Fig. 4 Trends in the number of chun salmon fry released fron Japan and of adults returned after four years to the nother country in aillions, the return rate in percent and the average body weight (three-year running nean) of returned fish in kilograns, for each year-class. 
year-class it falls to a level 16 years before in the course of four years, though the releases have been kept at a high level. Return rate for salmon is, in other words, survival rate during their marine lives and we could not explain as an effect of the technology innovation its sudden about-face from the steep rise to the dramatic fall.

On the other hand, catches of the pink, chum, and sockeye salmon in the North Pacific since 1925, which can be regarded as proxies for biomass because the average body weight of returned fish had been negatively correlated to the catch $^{8}$ ), show variational patterns similar to each other; there were peaks in the late 1930 s, followed by a long period of low level, and catches rose steeply in the mid-1970s ${ }^{9}$. After a high level continued until the mid-1990s, catches went down. The trend in biomass of salmon in the whole North Pacific corresponds well with the fluctuation patterns of returns and return rates of chum salmon to Japan.

\section{VARIABILITY OF THE CLIMATE-OCEAN SYSTEM}

In Fig.5 are indicated three timeseries, SOI (Southern Oscillation Index),SST (Sea Surface Temperature) anomaly in Area A (5N-5S,160E-150W) and in Area D $(15 \mathrm{~N}-0,130 \mathrm{E}-150 \mathrm{E})$. Levels (long-term averages) of these timeseries shifted discontinuously in 1976 and 1998, signifying that a conversion in average conditions of climate-ocean system in the equatorial Pacific, the regime shift, occurred.

Beamish et al. ${ }^{10)}$ examined nine climate-ocean indices and detected significant shifts which occurred

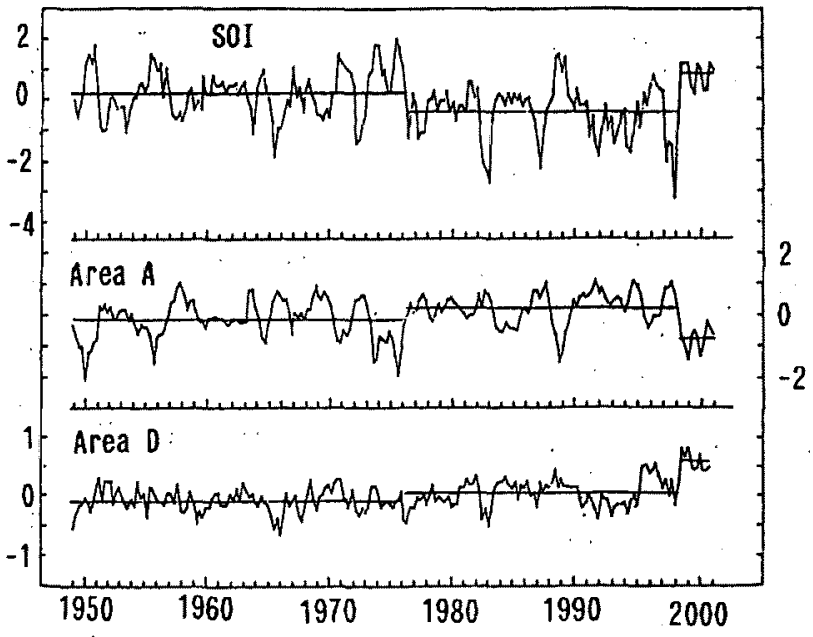

Fig. 5 Tineseries of quarterly averages of soI in $\mathrm{hPa}, \mathrm{SST}$ anomaly for Area $A(5 \mathrm{~N}-5 \mathrm{~S}, 160 \mathrm{E}$ $-15 O H)$ and for Area $O(15 N-0,130 \mathrm{t}-150 \mathrm{E})$ in Celsius. Horizontal bar denotes a wean of the tiveserios for each period covered with the bar. in 1925, 1947 and 1977. Not all indices exhibit changes at the same time with the general exception of 1977 . They state, " The 1977 regime shift is a key event in a number of studies and tends to be global in nature, which implies that a common event may precipitate shifts in the many climate-ocean systems studied." The most recent shift having taken place in the equatorial Pacific in 1998 ( Fig.5) is also found in the North Pacific ${ }^{11}$, which shows the shift in the late 1990s is basinwide in nature. The global-scale climate-ocean shift which came about in the mid1970s (1976/1977) seems to have caused such shifts in the marine ecosystems as occurring for anchovies, sardines, tunas and salmon.

Regarding the truly effective climate linkage mechanisms which acts to synchronize variability in many of the largest and most important fish populations of the world, $\mathrm{Uz}$ et al. ${ }^{12)}$ analyzed remotely sensed chlorophyll and sea-surface height data and showed that $1000-\mathrm{km}$-scale Rossby waves, which propagate in a westward direction in the oceans, are associated with about 5 to $20 \%$ of the observed variability in chlorophyll concentration. According to Siegel ${ }^{13)}$, Rossby waves may act like a rototiller, "turning over" upper-ocean nutrient in their path.

\section{BIOLOGICAL PROCESSES OF THE REGIME SHIFT}

There is a close inverse relation between the individual growth of fish and the biomass of the Far Eastern sardine population (Fig. 6) ${ }^{14}$, which implies that under smaller biomass higher individual growth will be expected from the increased per-capita ration, and vice versa. When a population remains at a low level under an environment unfavorable to it, the individual nutritional condition of spawners will be ameliorated, and the fish grow faster and produce higher-quality eggs and spermatozoa. However, the hatched larvae will find it hard to survive under the conditions against the whole population and the range of the population is restricted to the coastal waters. When the environment, especially the food conditions for the early survival, is improved by the climate change, better conditions will emerge for the higherquality larvae to survive. This is the densityindependent, growing phase of the population.

As the population becomes more abundant and its range wider offshore, an individual fish suffers a reduced per-head food supply and an energy loss from active swimming, which leads to a smaller fish size. The population becomes denser, and eggs and spermatozoa will be deteriorated. When the population becomes extremely overcrowded, the early 


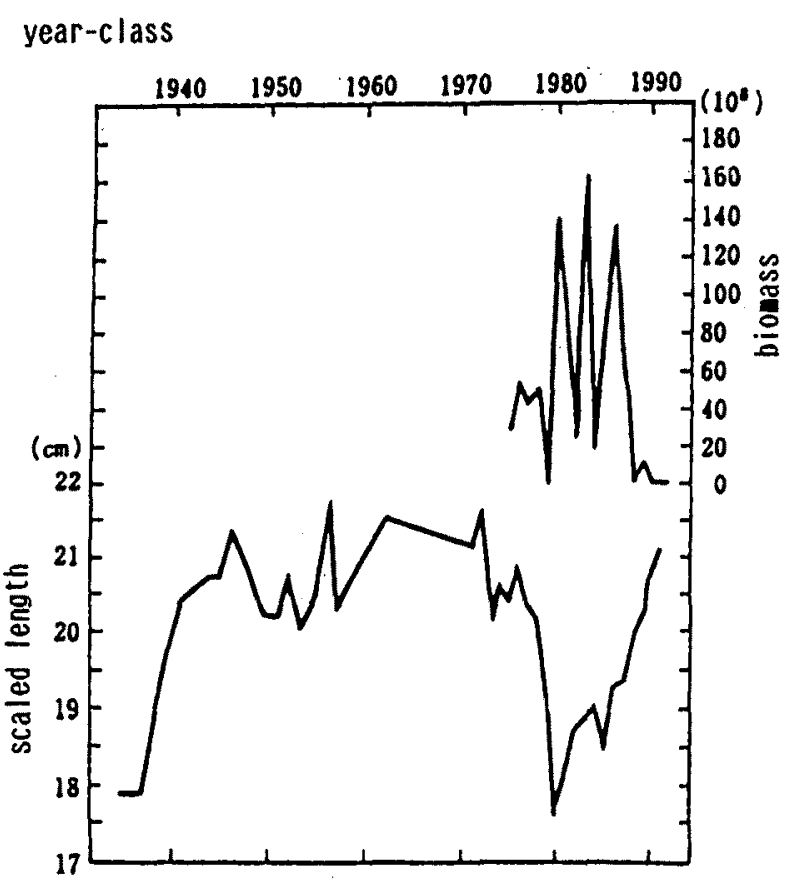

FIG. 6 Tineseries of the bionass of one-year recruits in the raters southeast of Hokkaido(top) and of the scaled length of three-year-old adults(botton) for the far Eastern sardinc population. When the bionass is larger, the sardine tend to appear in the northern waters.

(kawasaki and omori ${ }^{14}$ ),

survival will fall independently of the environmental conditions. This is the density-dependent, falling phase of the population. Environmental advantages to a population are inconsistent with those to an individual fish and the inconsistency is a dominating force to drive the fish population to fluctuate .

In short, although it is the nutritional conditions of the spawners that matters to the survival of eggs, for the growing phase of the population the conditions must be linked with amelioration of the environment ( density-independent factor), while for the falling phase with overpopulation under the extended range (density-dependent factor).

Marshall et al. ${ }^{15)}$ examined a relation between the HSI, hepatosomatic index (liver weight/body weight ), of the spawners and the three-year recruits of the Barents Sea cod. Strong year-classes have never occurred at low HSIs and the abundance of recruits jumps up only after the HSI exceeds $6 \%$. It is not the biomass but the condition of spawners that defines the subsequent year-class strength.

\section{REGIME SHIFT AND THE STOCK MANAGEMENT AND ENHANCEMENT}

In the traditional population dynamics that has underlain the current stock management and enhancement regimes, it is assumed that a fish population is in equilibrium with the fishing effort under average environmental conditions. The theory presupposes that a fish population is controlled solely by regulating fishing effort or is. enhanced by improving the release techniques.

As explained earlier, however, fluctuations in fish populations are driven just by the global climate change, neither by the fishing effort nor by the enhancement techniques. According to the surplus production model, one of the two major models of population dynamics, established by Schaefer ${ }^{16}$ for the yellowfin tuna fishery in the eastern tropical Pacific, the CPUE is expected to be negatively regressed against the fishing effort. However, tuna populations are fluctuating in a manner independent of the fishing effort ( Fig.2). The population dynamics has turned out often inconsistent with the real world and it needs be examined.

A novel discipline is expected to be worked out, which could explain and foresee from the historical and earth scientific viewpoints the variability in the marine ecosystems and fish populations, based on the regime shift theory.

\section{ACKNOWLEDGEMENTS}

The present author appreciates the kindness done by Drs. Yoshinari Tsuruta and Yukimasa Ishida, the National Hokkaido Fisheries Research Institute, Fisheries Research Agency, Japan, for providing him with the chum salmon enhancement data.

\section{REFERENCES}

1. Kawasaki $T$. Why do some pelagic fishes have wide fluctuations in their numbers ? - Biological basis of fluctuation from the viewpoint of evolutionary ecology FAO Fish. Rept. $1983 ; 291$ : 1066-1078.

2. Venrick EL, McGown JA,Gayan DR, Hayward DL. Climate and chlorophyll a : Long-term trends in the central Pacific. Science $1987 ; 238$ : 70-72.

3. Brodeur $\mathrm{RD}$, Ware $\mathrm{DM}$. Long-term variability in zooplankton biomass in the subarctic Pacific Ocean. Fish. Oceanogr. 1992; 1: 32-38.

4. Clark WC, Hare ST, Parma AM, Sullivan PJ, Trumble PJ. 
Decadal changes in growth and recruitment of Pacific halibut ( Hippoglossus stenolepis). Can. J. Fish. Aquat. Sci. $1999 ; 56: 242-252$.

5. Kawasaki T. Fisheries Resources - All at sea when they come to management ? Seizando-Shoten Publisher, Revised edition $2000 ; 230$ pp. (in Japanese ).

6. Nihira A. Studies on the behavioral ecology and physiology of migratory fish schools of skipjack tuna (Katsuwonus pelamis) in the oceanic frontal area, Bull. Tohoku Natl. Fish. Res. Inst. 1996; 58: 137-233 (in Japanese ).

7. Fisheries Agency, the Japanese Government. White paper on the Japanese fisheries for the year 19981999 ; 350 pp. (in Japanese ).

8. Bigler BS, Welch DW, Helie ЛH. A review of size trends among North Pacific salmon (Oncorhynchus spp.). Can. J. Fish. Aquat. Sci. 1996 ; 53 : 1002-1016.

9. Beamish RJ, Bouillon DR. Pacific salmon production trends in relation to climate . Can. J. Fish. Aquat.Sci. 1993; 50 : 1002-1016.

10. Beamish RJ, McFarlane GA, King JR. Fisheries climatology : Understanding decadal scale processes that naturally regulate British Columbia fish populations. In
Harrison DH, Parsons TR (eds) Fisheries Oceanography. An integrative approach to fisheries ecology and management. Blackwell Science 2000; 74-130.

11. Schwing ES. The $1998-99$ regime shift in the North Pacific : physical mechanisms and ecological consequences, presented at the PICES Tenth Anniversary Meeting October 5-8, 2001.

$12 \mathrm{Uz} \mathrm{BM}$, Yodder JM, Osychny V. Pumping of nutrients to ocean surface water by the action of propagating planetary waves. Nature 2001; 409: 597-600.

13. Siegel DA. The Rossby rototiller. Nature $2001 ; 409$ : 576-577.

14. Kawasaki T, Omori M. Possible mechanisms underlying fluctuations in the Far Eastern sardine population inferred from the time series of two biological traits. Fish. Oceanogr. 1995; 4 : 238-242.

15. Marshall CT, Naragina NA, Lambert Y, Kjesbu OS. Total lipid energy as a proxy for total egg production by fish stocks, Nature 1999; 402 : 288-290.

16. Schaefer MB. A history of the dynamics of the fishery for yellowfin tuna in the eastern tropical Pacific Ocean. InterAmer. Trop. Tuna Comm. Bull. 1957; 1 : 90-136. 